\title{
Thermal Analysis of Air-Core Power Reactors
}

\author{
Zhao Yuan, Jun-jia He, Yuan Pan, Xiao-gen Yin, Can Ding, Shao-fei Ning, and Hong-lei Li \\ State Key Laboratory of Advanced Electromagnetic Engineering and Technology, Huazhong University of Science and Technology, \\ Wuhan 430074, China \\ Correspondence should be addressed to Yuan Pan; panyuan@mail.hust.edu.cn
}

Received 28 January 2013; Accepted 26 February 2013

Academic Editors: B. Chan, J. K. Chen, J.-I. Jang, and G.-J. Wang

Copyright ( 2013 Zhao Yuan et al. This is an open access article distributed under the Creative Commons Attribution License, which permits unrestricted use, distribution, and reproduction in any medium, provided the original work is properly cited.

\begin{abstract}
A fluid-thermal coupled analysis based on FEM is conducted. The inner structure of the coils is built with consideration of both the structural details and the simplicity; thus, the detailed heat conduction process is coupled with the computational fluid dynamics in the thermal computation of air-core reactors. According to the simulation results, $2 \mathrm{D}$ temperature distribution results are given and proved by the thermal test results of a prototype. Then the temperature results are used to calculate the heat flux to predict the detailed heat transfer process in the packages of the reactors. The study in this paper may be useful in the design optimization in air-core reactors.
\end{abstract}

\section{Introduction}

With the development of power system, the usage amount of power reactors continues to rise more and more large capacity air-core reactors appear. Air-core reactors with large capacities have more packages and greater heights, which may cause uneven distribution of temperature rise. Thus, the accurate temperature field computational methods are in need.

Numerical simulation has been used to analyze the thermal condition of power equipment for a long time. Two categories of numerical approaches were developed as "Network Modeling" [1-6] and finite element method (FEM) [7-10]. The former can describe the heat transfer process clearly, but can only be used when critical temperatures such as hot spots are required and detailed local flow/temperature information is not [5]. The latter is adopted more and more due to its pinpoint accuracy and the detailed information it can provide.

Air-core reactors have complex structures with paralleled cylinder packages and vertical air ducts. The heat transfer in them is a hybrid process with heat conduction, convection, and radiation. Thus FEM is obviously better suited than the other computational methods in the thermal computation of air-core reactors. In [11, 12], 2D and 3D fluid-thermal field coupled FEM models are built to compute the temperature field of power transformers and reactors. But the inner structures were not considered and the details of temperature distribution and heat transfer process are not analyzed.

In this paper, a fluid-thermal coupled analysis based on FEM is conducted. The inner structure of the coils is built with consideration of both the structural details and the simplicity; thus, the detailed heat conduction process is coupled with the computational fluid dynamics in the thermal computation of air-core reactors. After the analysis, $2 \mathrm{D}$ temperature distribution results are given and proved by the test results of a prototype. Then the temperature results are used to calculate the heat flux to predict the detailed heat transfer process in the packages of the reactors. The study in this paper may be useful in the design optimization in air-core reactors.

\section{Materials and Methods}

2.1. Structure and Parameters of an Air-Core Reactor Prototype. The typical air-core power reactor contains some cylindrical packages connected in parallel and the vertical air ducts between them, as it is shown in Figure 1. The packages comprise metal conductors and the insulating material. The air ducts between the packages are used as heat dissipation channels of the packages. 


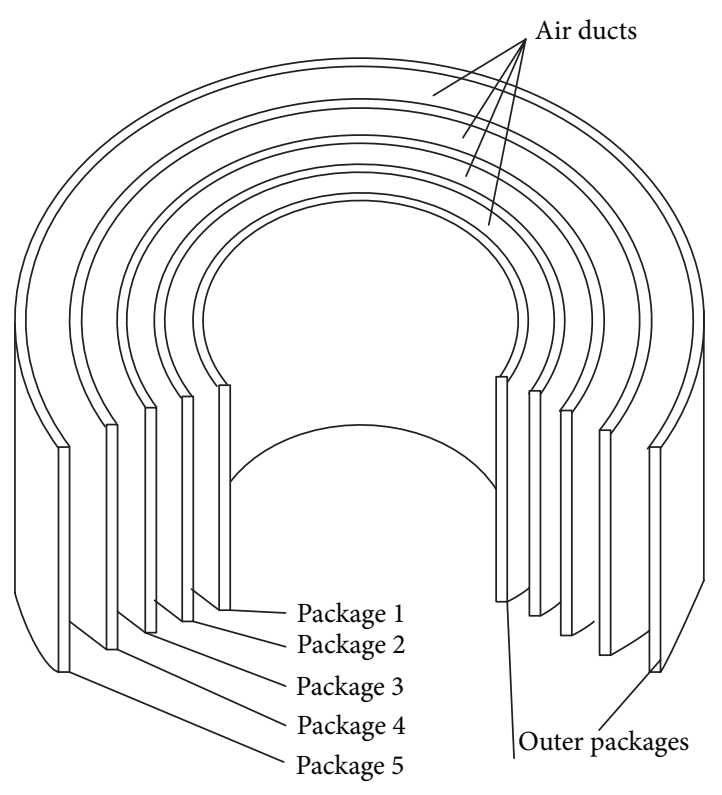

FIGURE 1: Structure sketch of air-core reactor.

In this paper, a prototype of air-core power reactor with five packages is taken as an example, the parameters of which are given in Table 1.

\subsection{Mathematical Modal}

2.2.1. Computation of Heat Load. The heat sources in the packages include the resistive current loss and extra eddy loss [13-15]. According to $[16,17]$ the total loss in a package can be simplified as $k_{c}$ times of resistive current loss; thus, the loss of the $i$ th coil can be expressed as

$$
P_{i}=\frac{\pi k_{c, i} J_{i}^{2} S_{i} W_{i} D_{i}}{\kappa}
$$

where $J_{i}$ is the ampere density of $i$ th coil, $W_{i}$ is the number of turns of $i$ th coil, $D_{i}$ is the diameter of $i$ th coil, $S_{i}$ is the total sectional area of the metallic conductor in the $i$ th package, and $\kappa$ is the conductivity of metal conductor.

2.2.2. Heat Transfer Equations. In most cases, heat transfer process contains heat conduction, convection, and radiation.

Partial differential equation of heat conduction is given as

$$
\frac{\partial^{2} t}{\partial x^{2}}+\frac{\partial^{2} t}{\partial y^{2}}+\frac{\phi}{\lambda}=0
$$

where $t$ is the temperature, $\phi$ is loss function, and $\lambda$ is the thermal conductivity of the considered material.

Heat convection process is closely related to the fluid states, which can be described by the continuity equation,
TABLE 1: The parameter of an air-core power reactor prototype.

\begin{tabular}{lcccc}
\hline Package number & $\begin{array}{c}\text { Diameter } \\
(\mathrm{m})\end{array}$ & $\begin{array}{c}\text { Current } \\
(\mathrm{A})\end{array}$ & $\begin{array}{c}\text { Ampere density } \\
\left(\mathrm{A} / \mathrm{m}^{2}\right)\end{array}$ & $\begin{array}{c}\text { Height } \\
(\mathrm{m})\end{array}$ \\
\hline 1 & 0.619 & 36.662 & $1.329 \times 10^{6}$ & 0.325 \\
2 & 0.684 & 31.081 & $1.329 \times 10^{6}$ & 0.325 \\
3 & 0.747 & 39.476 & $1.329 \times 10^{6}$ & 0.325 \\
4 & 0.811 & 44.049 & $1.329 \times 10^{6}$ & 0.325 \\
5 & 0.880 & 58.732 & $1.329 \times 10^{6}$ & 0.325 \\
\hline
\end{tabular}

the momentum equation, and the energy equation as shown in (3) the following equation:

$$
\begin{gathered}
\frac{\partial u}{\partial x}+\frac{\partial v}{\partial y}=0 \\
\rho\left(u \frac{\partial u}{\partial x}+v \frac{\partial u}{\partial y}\right)=F_{x}-\frac{\partial p}{\partial x}+\eta\left(\frac{\partial^{2} u}{\partial x^{2}}+\frac{\partial^{2} u}{\partial y^{2}}\right) \\
\rho\left(u \frac{\partial v}{\partial x}+v \frac{\partial v}{\partial y}\right)=F_{y}-\frac{\partial p}{\partial y}+\eta\left(\frac{\partial^{2} v}{\partial x^{2}}+\frac{\partial^{2} v}{\partial y^{2}}\right) \\
u \frac{\partial t}{\partial x}+v \frac{\partial t}{\partial y}=\frac{\lambda}{\rho c_{p}}\left(\frac{\partial^{2} t}{\partial x^{2}}+\frac{\partial^{2} t}{\partial y^{2}}\right)
\end{gathered}
$$

where $u$ and $v$ are velocities, $\rho$ is density, $F_{x}$ and $F_{y}$ are $x$ and $y$ component of volume force, $p$ is pressure, $\eta$ is dynamic viscosity of fluid, and $c_{p}$ is specific heat at constant pressure.

The heat radiation can be described by

$$
q=\varepsilon \sigma\left(T_{R}^{4}-T_{A}^{4}\right)
$$

where $q$ is the heat flux density, $\varepsilon$ is the emissivity, $\sigma$ is the Stefan-Boltzmann number, $T_{R}$ is the temperature of the radiating surface, and $T_{A}$ is the temperature of a receiving surface.

In air-core reactors, most of the packages' surfaces face the surface of another package, on which the temperature is nearly the same. Thus, for air-core reactors, the radiating heat transfer can be neglected according to (4).

\subsection{Fluid-Thermal Coupled Analysis}

2.3.1. Finite Element Model. According to the mathematical modal mentioned above, a fluid-thermal coupled analysis should be adopted. A 2D axial symmetry finite element model in Flotran is built to conduct the analysis.

The simulation model is comprised of five packages and four vertical air ducts. Rectangles are chosen to replace the real cross sections of metal conductors and insulating materials to simplify the modeling. But, in order to study the detailed distribution in the packages, the metal conductor is divided into three parts in the radial direction and 15 parts in the axial direction, as shown in Figure 2(a). 


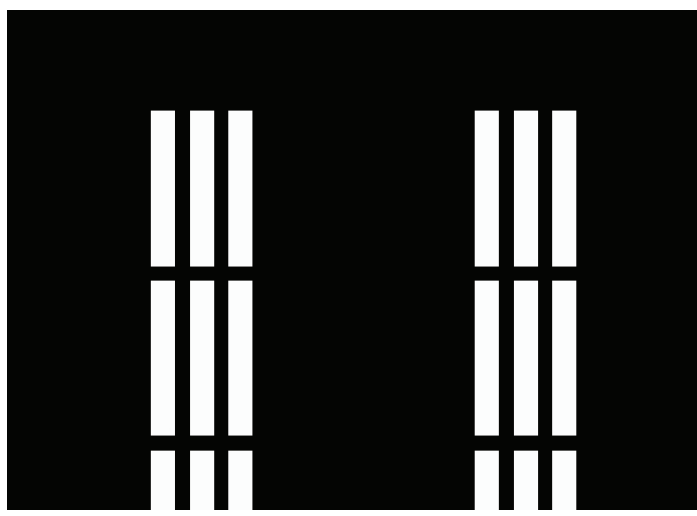

(a)

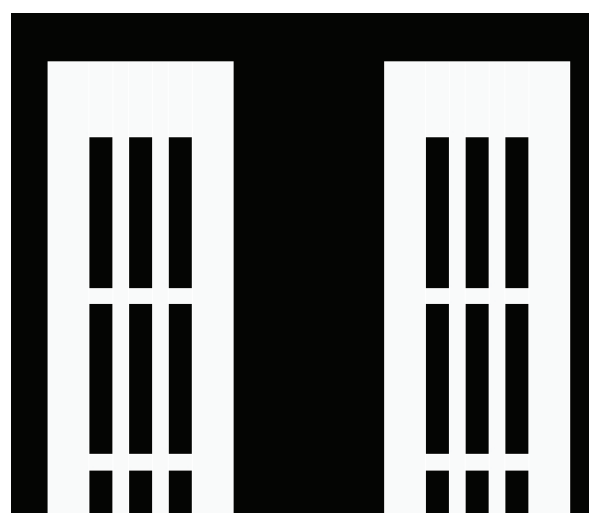

(b)

FIgURE 2: (a) Metallic conductors. (b) Insulating material.

In the rectangles that indicate the metal conductors, equivalent surface heat densities computed according to (5) are loaded:

$$
\begin{gathered}
Q_{f, i}=\frac{k_{c, i} J_{\mathrm{eq}, i}^{2}}{\kappa}, \\
J_{\mathrm{eq}, i}=\frac{J_{i} S_{i} W_{i}}{(45 a b)},
\end{gathered}
$$

where $J_{\mathrm{eq}, i}$ is the equivalent ampere density, $a$ is the length of the rectangle in the radial direction, and $b$ is the length of the rectangle in the axial direction.

The insulating materials are also plotted as a combination of rectangles as shown in Figure 2(b). The thermal conductivity of the insulating materials in the finite element model $\lambda_{m}$ is defined according to

$$
\lambda_{m} d=\lambda d_{m}
$$

where $d$ is the real length of insulating materials along the heat conduction direction, and $d_{m}$ is the corresponding equivalent length in the finite element model.

2.4. Boundary Conditions. The boundary conditions of the analysis are set as follows.

(a) Rotational symmetry conditions are defined on the left boundary line, the radial velocity of which is defined as 0 .

(b) The radial and axial velocities of all the fluid-solid interface in the analysis model are set 0 . The roughness coefficient of the packages' surfaces is set 0.2.

(c) In the right boundary, the temperature is set $20^{\circ} \mathrm{C}$, the relative pressure is set 1 , and the velocities in all directions are set 0 .

(d) In the lower boundary, the temperature is set $20^{\circ} \mathrm{C}$, the velocities in all directions are set 0 , and the pressure is defined variable.

(e) In the lower boundary, the temperature, the pressure, and the velocities in all directions are defined variable.

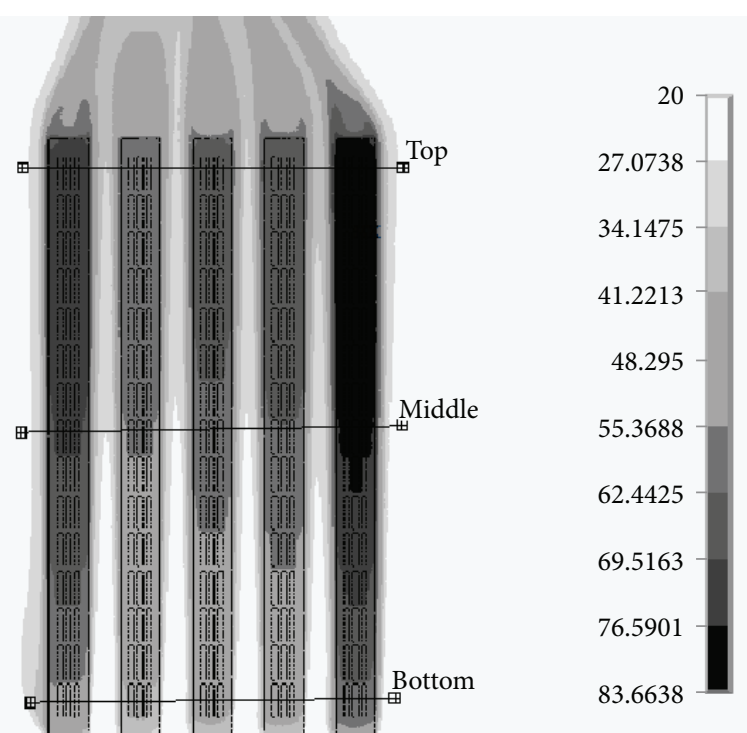

FIGURE 3: Temperature field of an air-core reactor prototype.

(f) The turbulence model is open and the SST turbulence model in Flotran is chosen to solve the problem.

\section{Results and Discussion}

After the analysis, results of temperature field, fluid velocity and the pressure distribution, and so on are given. According to the abovementioned results the temperature distribution regulatory and the heat transfer processes of air-core power reactors are studied.

3.1. Analysis of Temperature Distribution. Temperature field of the analyzed area is given in Figure 3.

The temperature field shown in Figure 3 agrees with the thermal test results of the prototype with parameters shown 


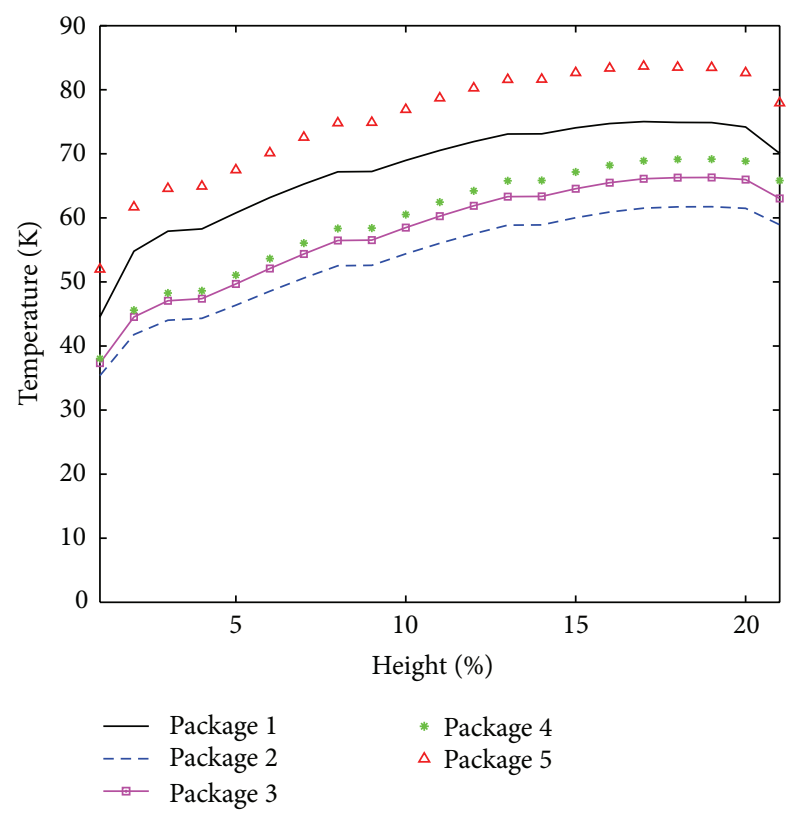

FIGURE 4: The axial temperature distribution along the midline of the packages.

in Table 1 and thus proves the computational accuracy of the coupled analysis.

Data of the temperature along the radial center of the packages are read and plotted as the curves shown in Figure 4.

Data of the temperature along the radial center of the vertical air ducts are read and plotted as the curves shown in Figure 5.

In order to study the temperature distribution and heat transfer in the radial direction, 3 horizontal paths are defined, as the horizontal lines shown in Figure 3. Temperature data along the paths are read and plotted as the curves shown in Figure 6.

According to Figures 3-6, the following can be seen.

In the axial direction of the packages, temperature rises from the bottom up. Due to the end effects the maximum temperature appears near $80 \%$ the package height.

Along the radial direction of the packages, the maximum temperature appears near the center of the package. Along the path from the center to the side surface, temperature declines slowly and nonlinearly, and the temperature gradient in the insulating material is bigger than that in the metal conductors.

In the air ducts, temperature rises linearly from the bottom up. In the radial direction, along the path from the center of the ducts to the packages' side surfaces, temperature rises nonlinearly. A remarkable temperature gradient appears in the lamina near the fluid-solid interface, which is defined as thermal boundary layer. From Figure 6 it can be seen that the thicknesses of thermal boundary layer also rise from the bottom up, which indicates the change of the fluid flow state.

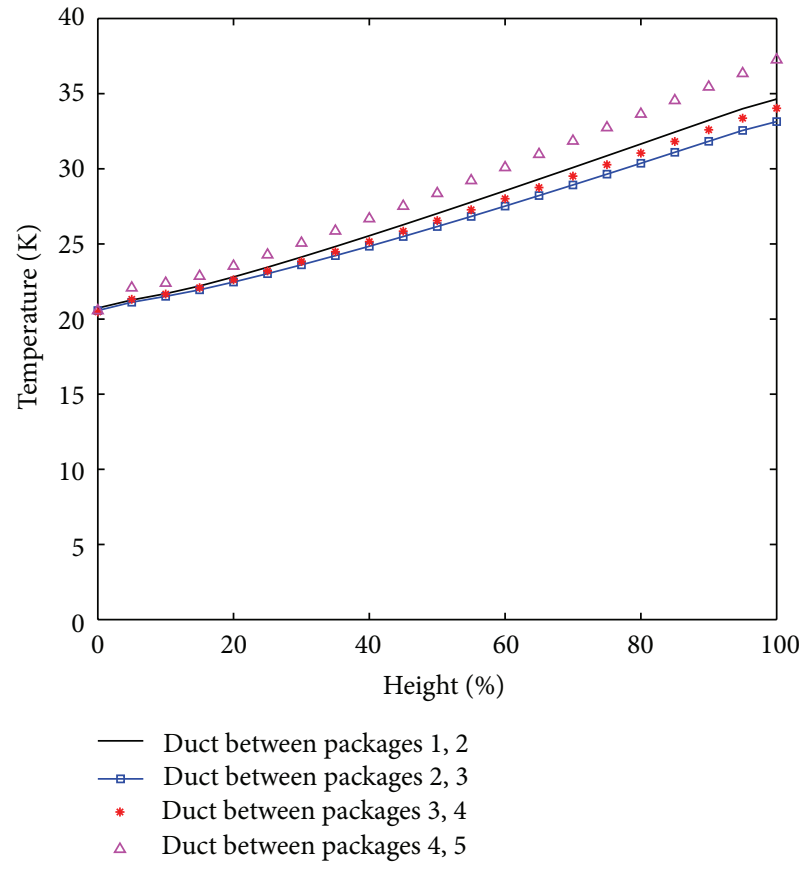

FIGURE 5: The axial temperature distribution along the midline of the vertical air ducts.

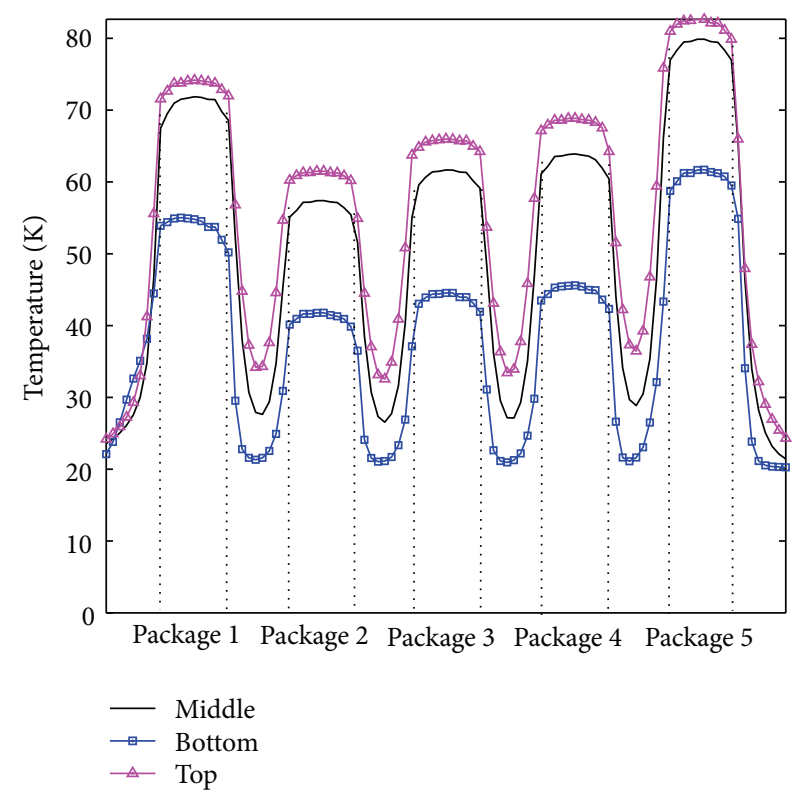

FIGURE 6: Radial temperature distribution along the "Bottom," "Middle," and "Top" paths defined in Figure 3.

3.2. Study of the Heat Transfer Process. Heat flux reflects the heat flow in the air-core reactor, which is a good tool to study the heat transfer process. Due to the complex construction, the heat flux inside the packages is hard to acquire. Thus, the heat flux passes through the surfaces of the packages are considered instead.

Using the temperature distribution results and conduction equation given in (2), the heat flux passes through 


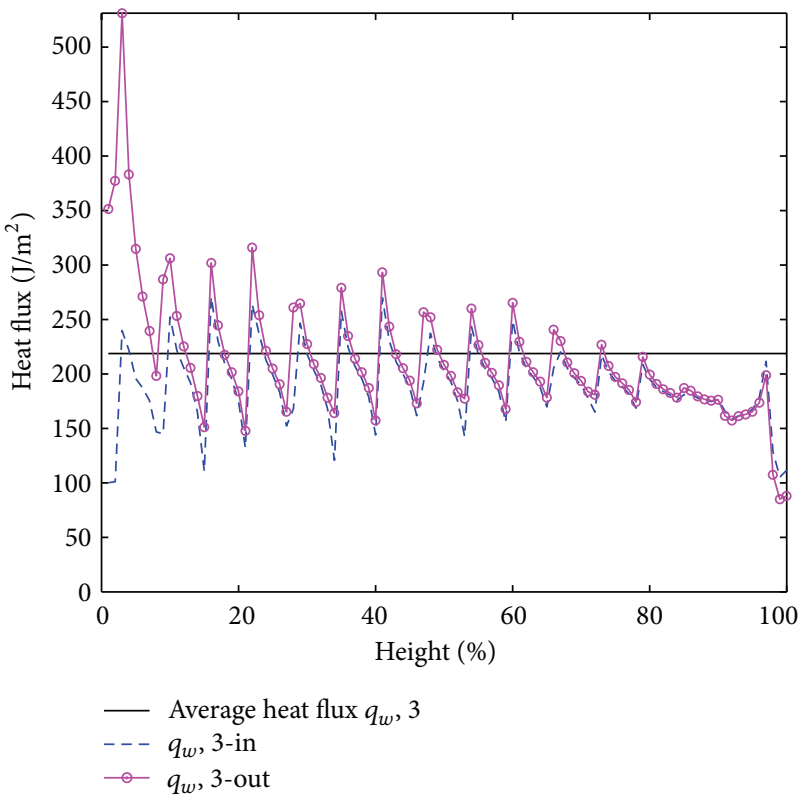

(a)

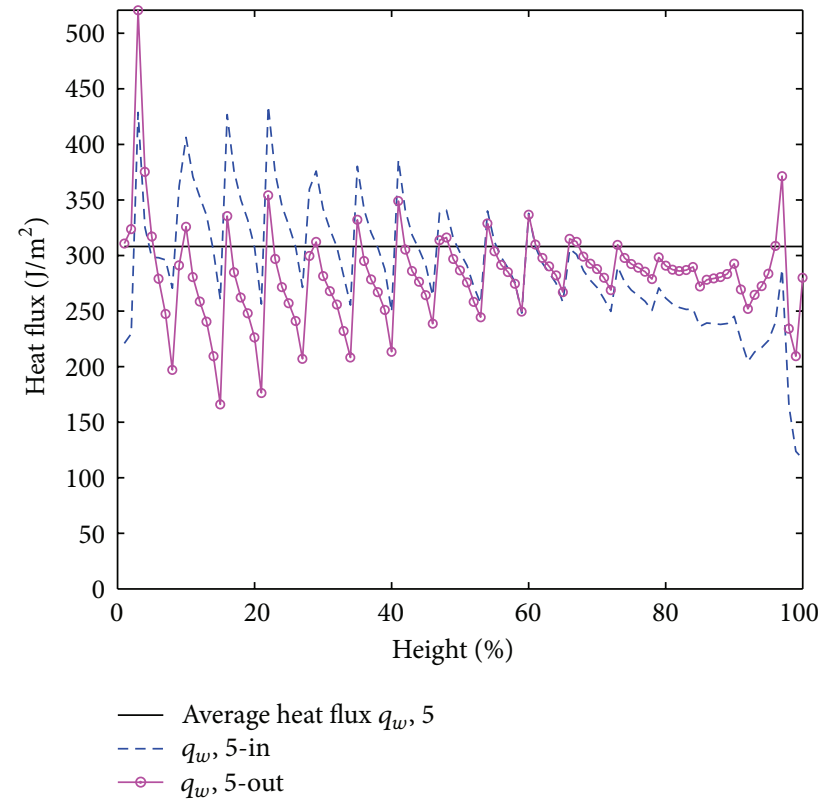

(b)

FIGURE 7: (a) The average heat flux and the axial heat flux through the inner and outer surfaces of the 3rd package. (b) The average heat flux and the axial heat flux through the inner and outer surfaces of the 5 th package.

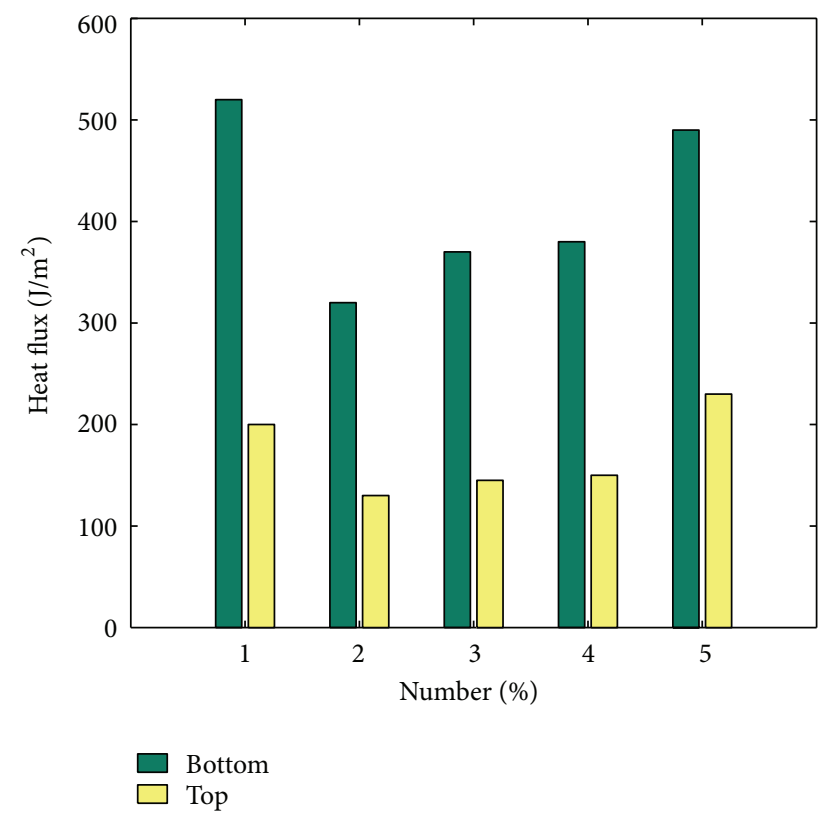

Figure 8: Axial heat flux through the bottom and top of the packages.

the packages' surfaces can be calculated. The heat fluxes go through the side surfaces of the 3rd and 5th packages' are given as the curves in Figures 7(a) and 7(b), the axial heat flux through the bottom and top of the coils are calculated as the columns in Figure 8. Meanwhile, the average heat flux $\bar{q}_{w, i}$ conducted through the surfaces of the packages can be calculated according to (1) and (7):

$$
\bar{q}_{w, i}=\frac{P_{i}}{A_{i}},
$$

where $A_{i}$ is the superficial area of the $i$ th package.

The results of $\bar{q}_{w, 3}, \bar{q}_{w, 5}$ are shown as the full straight lines in Figures 7(a) and 7(b).

From Figures 7 and 8 the following can be seen.

Most of the heat load generated inside the packages are dissipated through the side surfaces of the packages and are carried away by the flowing air. A small part of the heat load dissipated through the bottom and top of the packages. The heat flux through the bottom surfaces is larger than that through the top surfaces.

For side surfaces that are facing the air ducts (inside surfaces), the envelope of the heat flux curves decline from the bottom up, which indicates that an axial heat flow goes from above to below inside the package. The mentioned axial heat flux is much smaller than the radial heat flux that goes through the side surfaces.

For inner packages, both the side surfaces of which face the air ducts, the heat flux through the two side surfaces equals each other. For outer packages, the side surfaces of which face the large air space (outside surfaces) and the air ducts (inside surfaces) separately, the heat convection in the air duct is stronger than that in the large air space, which indicates a heat flux from the outer part of the outer packages into the inside surface.

Near the entrance of the air ducts, the local temperature difference between the conductors and air is relatively small, 
but the local heat flux is considerably higher due to a stronger local heat convective effect.

\section{Conclusion}

The agreement of the thermal results between the analysis and the prototype testing proves the computational accuracy of the fluid-thermal coupled analysis.

The fluid-thermal coupled analysis gives more details than the prototype tests. The computational results of temperature field, fluid velocity distribution, and so forth can be used to study the field distribution of a design and thus are useful to judge its reliability.

By means of the data obtained in the fluid-thermal coupled analysis, the heat transfer process, including the heat conduction in the packages and the thermal conduction/convection process in the ducts and large air spaces, can be studied distinctly. As a result, the temperature distribution results could be explained. Furthermore, the study results of detailed heat transfer process in this paper could be used to optimize the heat load distribution in the packages, as well as the structural improvement of the packages and air ducts.

\section{Acknowledgments}

The authors wish to thank The Ministry of Science and Technology of the People's Republic of China for financial support in the National Key Technology R\&D Program (2009BAA19B00).

\section{References}

[1] E. I. Amoiralis, P. S. Georgilakis, T. D. Kefalas, M. A. Tsili, and A. G. Kladas, "Artificial intelligence combined with hybrid FEM-BE techniques for global transformer optimization," IEEE Transactions on Magnetics, vol. 43, no. 4, pp. 1633-1636, 2007.

[2] A. J. Oliver, "Estimation of transformer winding temperatures and coolant flows using a general network method," IEE Proceedings C: Generation Transmission and Distribution, vol. 127, no. 6, pp. 395-405, 1980.

[3] Z. R. Radakovic and M. S. Sorgic, "Basics of detailed thermalhydraulic model for thermal design of oil power transformers," IEEE Transactions on Power Delivery, vol. 25, no. 2, pp. 790-802, 2010.

[4] E. A. Simonson and J. A. Lapworth, "Thermal capability assessment for transformers," in Proceedings of the 2nd International Conference on the Reliability of Transmission and Distribution Equipment, pp. 103-108, March 1995.

[5] A. Weinlader, W. Wu, S. Tenbohlen, and Z. Wang, "Prediction of the oil flow distribution in oil-immersed transformer windings by network modelling and computational fluid dynamics," Electric Power Applications, IET, vol. 6, pp. 82-90, 2012.

[6] J. Zhang and X. Li, "Coolant flow distribution and pressure loss in ONAN transformer windings-part I: theory and model development," IEEE Transactions on Power Delivery, vol. 19, no. 1, pp. 186-193, 2004.

[7] E. J. Kranenborg, C. O. Olsson, B. R. Samuelsson, L. Å. Lundin, and R. M. Missing, "Numerical study on mixed convection and thermal streaking in power transformer windings," in
Proceedings of the 5th European Thermal-Sciences Conference, Eindhoven, The Netherlands, 2008.

[8] K. M. Takami, H. Gholnejad, and J. Mahmoudi, "Thermal and hot spot evaluations on oil immersed power Transformers by FEMLAB and MATLAB software's," in Proceedings of International Conference on Thermal, Mechanical and Multi-Physics Simulation Experiments in Microelectronics and Micro-Systems (EuroSime '07), pp. 1-6, April 2007.

[9] F. Torriano, M. Chaaban, and P. Picher, "Numerical study of parameters affecting the temperature distribution in a disc-type transformer winding," Applied Thermal Engineering, vol. 30, no. 14-15, pp. 2034-2044, 2010.

[10] A. Weinläder and S. Tenbohlen, “Thermal-hydraulic investigation of transformer windings by CFD-modelling and measurements," in Proceedings of the 16th International Symposium on High Voltage Engineering, Cape Town, South Africa, 2009.

[11] J. Smolka and A. J. Nowak, "Shape optimization of coils and cooling ducts in dry-type transformers using computational fluid dynamics and genetic algorithm," IEEE Transactions on Magnetics, vol. 47, no. 6, pp. 1726-1731, 2011.

[12] X. Yan, Z. Dai, Y. Zhang, and C. Yu, "Fluid-thermal field coupled analysis of air core power reactor," in Proceedings of the 6th International Conference on Electromagnetic Field Problems and Applications (ICEF '12), pp. 1-4, 2012.

[13] P. E. Burke and T. H. Fawzi, "Effect of eddy losses on the design and modelling of air-cored reactors," IEEE Transactions on Magnetics, vol. 27, no. 6, pp. 5001-5003, 1991.

[14] J. Wei, F. Lijun, and X. Tianwei, "The analysis of the Eddy losses for dry type air cored reactor," Journal of Shenyang Institute of Technology, pp. 79-82, 1999.

[15] S. R. Thondapu, M. B. Borage, Y. D. Wanmode, and P. Shrivastava, "Improved expression for estimation of leakage inductance in E core transformer using energy method," Advances in Power Electronics, vol. 2012, Article ID 635715, 6 pages, 2012.

[16] Q. Yu and S. A. Sebo, "Accurate evaluation of the magnetic field strength of large substation air-core reactor coils," IEEE Transactions on Power Delivery, vol. 13, no. 4, pp. 1114-1119, 1998.

[17] Q. Yu and S. A. Sebo, "Simplified magnetic field modeling and calculation of large air-core reactor coils," IEEE Transactions on Magnetics, vol. 32, no. 5, pp. 4281-4283, 1996. 

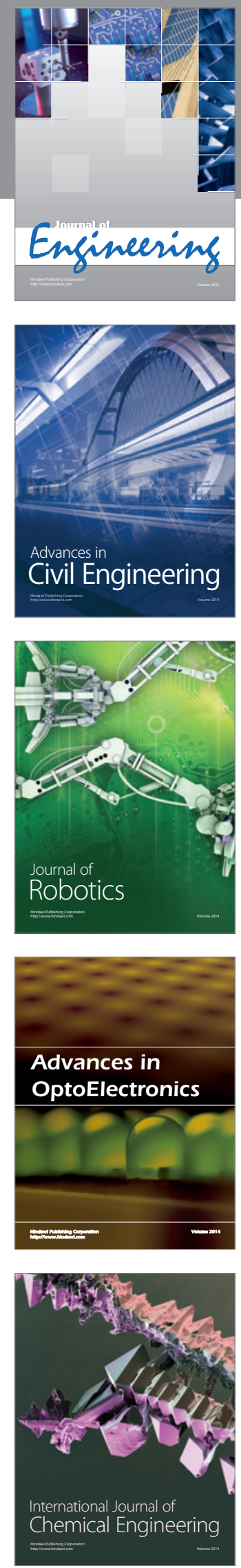

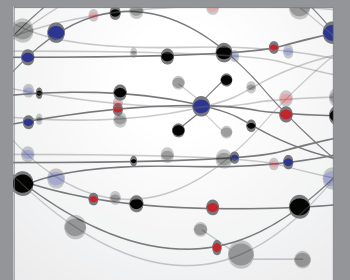

The Scientific World Journal
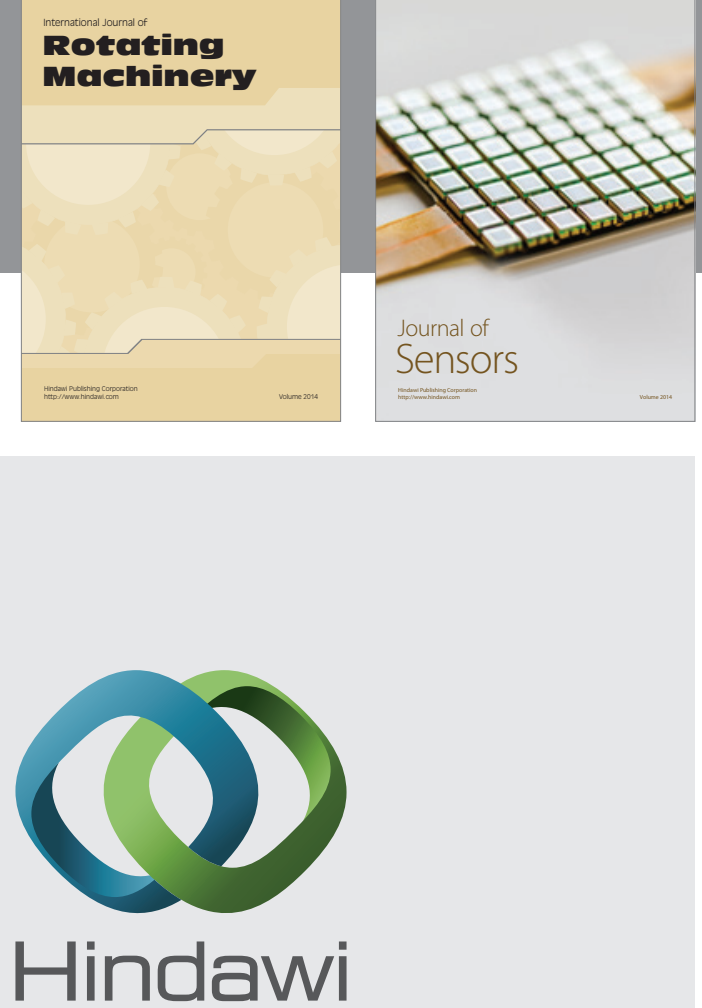

Submit your manuscripts at http://www.hindawi.com
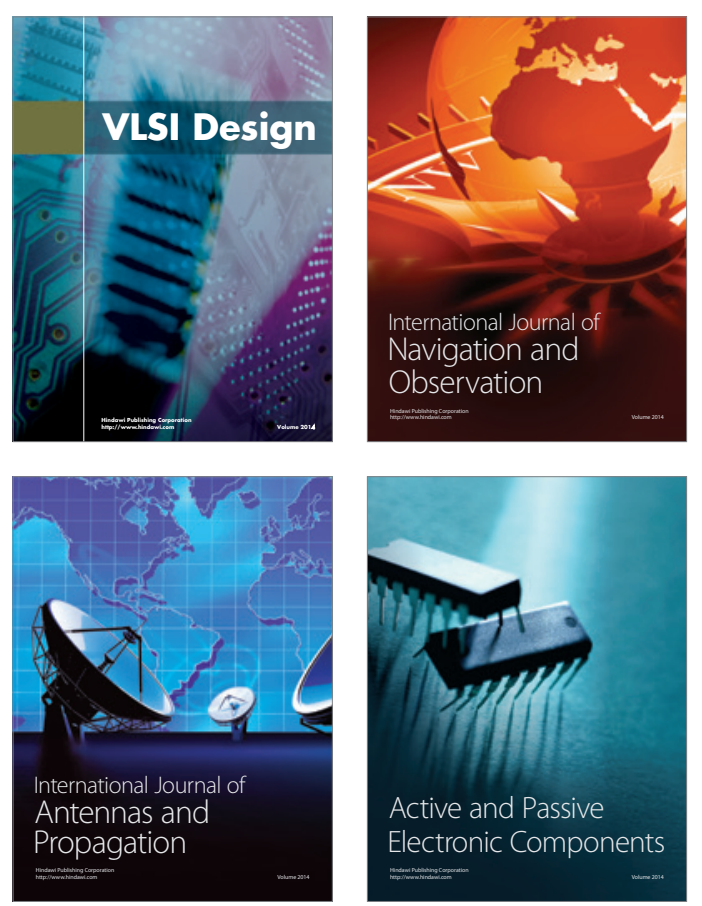
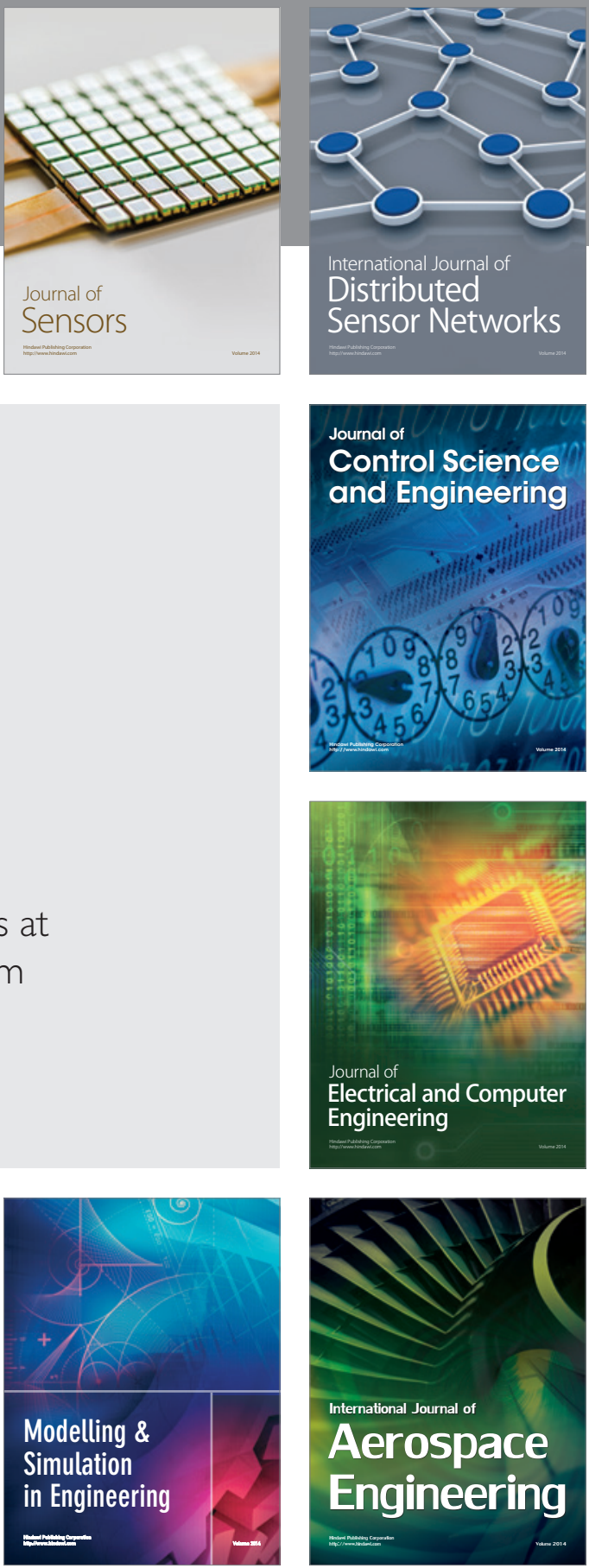

Journal of

Control Science

and Engineering
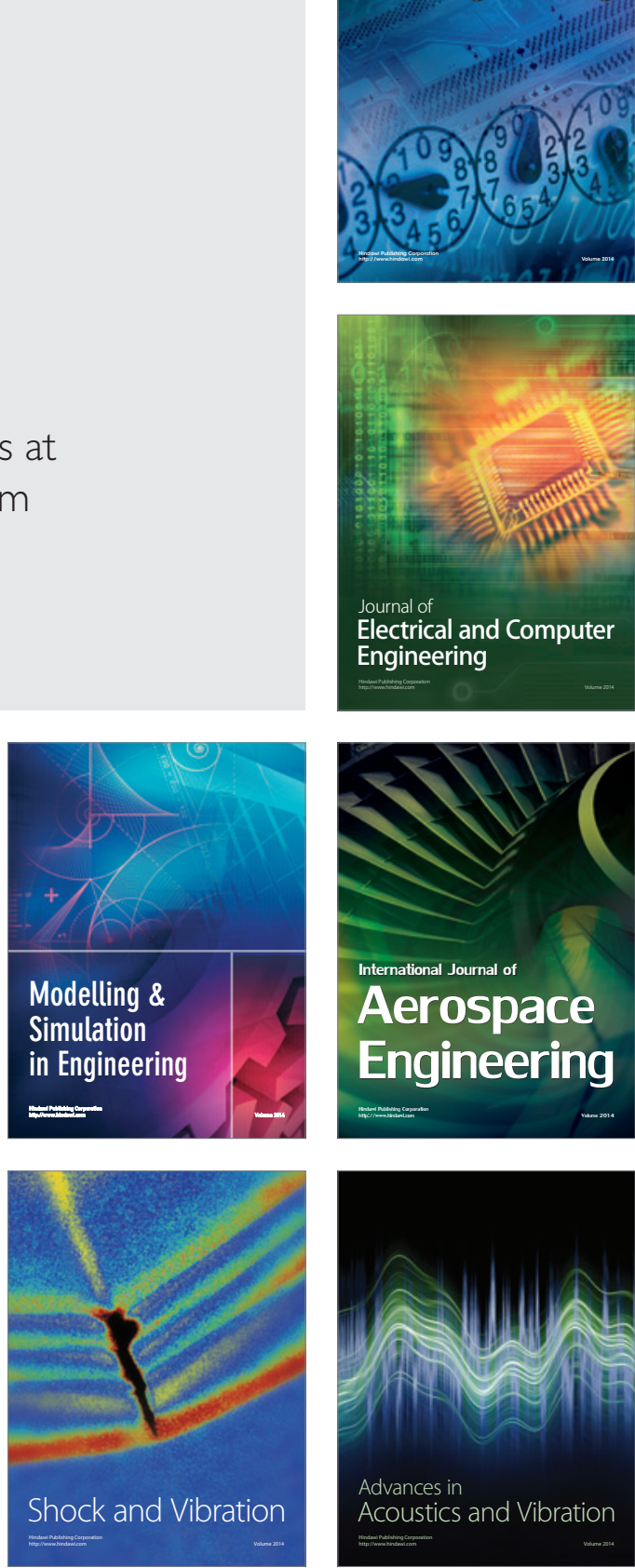